UDK 615.9

\title{
MODERN CHEMICAL FACTORS' RISK AND IMPACT MANAGEMENT INTERNATIONAL REQUIREMENTS AND THEIR IMPLEMENTATION IN THE SYSTEM OF STATE SANITARY-EPIDEMIOLOGIC CONTROL
}

\author{
Kh.Kh. Khamidulina \\ Federal Budgetary Health Establishment «Russian Register of Potentially Hazardous Chemical \\ and Biological Substances» under the Federal Service for Surveillance on Consumer \\ Rights Protection and Human Well-being of the Russian Federation, \\ Russian Federation, Moscow, Varshavskoe shosse, 19A, 117105 \\ State Budgetary Educational Institution of Additional Professional Educations «Russian Medical Academy of \\ Post-Graduate Education», Russian Federation, Moscow, 2/1 Barrikadnaya St., 123995
}

\begin{abstract}
The analysis performed of modern trends in chemicals handling and implementation in the RF and abroad showed the understanding that the chemical factor poses an integral hazard to human health and the environment and requires significant conjoint efforts to regulate it as well as the necessity to harmonize domestic regulatory and methodological bases with international requirements; to implement GLP and GHS into the hygiene and preventive toxicology practice; to create and implement a national program in systemic investigations into substances publicly traded on the market in order to withdraw those posing a high risk from circulation and replace them by safer alternatives.
\end{abstract}

Key words: chemical substance, hazard, risk.

In everyday life, we are exposed to more than 63000 chemical compounds, many of which do not have not passed sufficient risk assessment [1]. Since the issue of chemical exposure is of great importance, state policy in the sphere of chemical safety focuses on preventing pollution, constantly decreasing and eliminating health and environmental risks associated with exposure to chemical substances and their mixtures 'from synthesis to disposal'.

Safe handling of chemical substances in the modern world should be based on the principles of sustainable development and "Green Chemistry" [3], which involve the use of substances for chemical synthesis and processes that completely eliminate or significantly reduce the risk of impact on public health and the environment.

The World Health Organization, the UNEP, the International Labor Organization (ILO) and the Organization for Economic Cooperation and Development (OECD) the European Union (EU), the United States, Canada, Japan, Australia, New Zealand, etc. are currently working on limiting the use of and developing safe alternatives (effective substitutes that have the most similar physicochemical properties, which reduce, eliminate or avoid adverse effects) to lead, phthalates, PFCs.

(C) Khamidulina Kh.Kh., 2014

Khamidulina Khalidia Khizbulaevna - DSc., Professor, Director, Head of the Chair (e-mail: director@rpohv.ru; tel.+7 499 9409787, fax +7 499 9409775). 
This raises a need for a national program that would study the circulation of chemical products in the market, remove high-risk chemical substances and mixtures from circulation, and replace them with safe alternatives. Unfortunately, the Draft Technical Regulation on the safety of chemical products (EurAsEC) does not include this activity.

The focus of the scientific world is the development of safety criteria for substances and materials, taking into account the priority of nanoscale compounds. Since 2007, by the initiative of the Federal Service for Supervision of Consumer Rights Protection and Human Welfare and pursuant to the "Concept of toxicological studies, risk assessment methodology, methods of identification and quantification of nanomaterials", more than 50 regulatory and procedural regulations have been introduced to govern toxicological, hygienic and biomedical research, sampling, identification and quantitative analysis, as well as procedures to control and supervise the products.

In accordance with the recommendations of the Strategic Approach to International Chemicals Management (SAICM / SAICM) and the OECD, special attention is given to the issues related to risk assessment and control of new chemicals. Thus, in accordance with the legislation of the EU, Australia, New Zealand, Canada, USA, China, Japan and some other countries, new substances are subject to authorization and can enter the market only after careful consideration of all the associated hazards and provided the availability of a safety report, which includes an assessment of the risks for all possible exposure scenarios.

In Russia, Article 43 of the Federal Law № 52-FZ of 30.03.1999 On the sanitary and epidemiological welfare of the population, provides that the following be subject to state registration: chemical and biological substances (and potentially hazardous products manufactured on their basis) put in production for the first time and never used before; certain types of products, including food products, imported to Russia for the first time. In 1992, Russia introduced a state registration procedure for potentially dangerous chemicals. It includes collecting and analyzing information about the chemicals, their physical and chemical, toxicological, and ecotoxicological properties, hygiene indicators, and then providing that information to the federal executive government, industries and all then interested parties in order to monitor and develop effective interventions to prevent adverse effects on human health and the environment.

Since July 1, 2010 in connection with the entry into force of the Customs Union Agreement on Sanitary Measures №28 of December 11, 2009, state registration applies only to a small part of chemical and petrochemical products circulating in the Customs Union. Thus a number of extremely and highly dangerous products: heavy metals and their derivatives, acids, 
alkalis, peroxides; aromatic hydrocarbons and their derivatives; petroleum products (HS codes TC: $26,27,28$, part 29), are not subject to state registration and mandatory certification, and are used in the market without any control, contrary to the traditions of domestic hygiene and preventive toxicology.

Today, an important place in the system of chemical substance and mixture regulation is taken by the harmonization of their classification and marking. For this purpose, the UN Globally Harmonized System of Classification and Labelling of Chemicals (GHS) is actively implemented; it is aimed at harmonizing approaches to risk assessment, classification and labeling of chemical substances and mixtures [4]. Currently, GHS is used in 67 countries. Urgent need to implement the GHS in the practice of domestic hygiene and toxicology is dictated by the need to perform RF obligations under international agreements, the desire to accede to the OECD, the reluctance of the Russian industry twice classify and label products for the domestic and foreign market.

The necessity to introduce GHS into Russia's hygiene and toxicology practice is explained by Russia's obligation to comply with the international agreement, willingness to join OECD, and unwillingness of Russian enterprises to categorize and label the products twice for the domestic and foreign markets.

Russia's willingness to integrate with the international community, entering the WTO, joining the OECD imposes new obligations. So mutual acknowledgement of the data between the countries is a mandatory condition of Russia's equal participation in OECD. This is impossible without a national Good Laboratory Practice (GLP) System, adoption of OECD's test method database and implementation of GHS in Russia's home toxicology practice. For the purpose of the current national program aimed at introducing good laboratory practice into the activities of the test centers (laboratories), Rospotrebnadzor has adopted (RF Government Decree №260-r dated December 28, 2012) a Departmental Program of Implementing Good Laboratory Practices into the Activities of Testing Centers (laboratories). As part of the Program, GLP inspector candidates are getting training, testing centers have been selected to introduce GLP, sanitary and epidemiological requirements to sustainable technical equipment and maintenance of research biological facilities (vivarium) have been developed, and a R1.2.315613 Guide on the assessment of toxicity and hazard of chemical substance and their mixtures to public health has been developed and introduced, a method of testing toxicity and hazard level of chemical substances and their mixtures as well as GHS principles and criteria have been presented to OECD.

Informational systems about the toxicity and hazard of chemical substances to public 
health and the environment are becoming of great importance in the system of chemical safety. They are oriented at analysis and making effective management decisions. Today Russia has several informational systems on clinical toxicology, technology-related chemical accidents, hazard of waste for the environment, assessment of construction materials hazard, air pollution, water pollution, sea bottom pollution as well as informational predictive system of substance toxicity based on the analysis of 'structure-activity' relation. The advantage of these systems is promptness of providing information, fast information processing, regular updates, and convenient presentation. At the same time, many of the indicated databases are aimed at very specific research objectives and are used by a small number of specialists.

The CHRIP, EnviChem, ESIS, GHS-J, HPVIS, HSDB, HSNO CCID, INCHEM, JECDB, NICNAS PEC, OECD HPV, SIDS UNEP, UK CCRMP Outputs, US EPA IRIS, US EPA SRS programs developed by the UNEP, ILO, OECD, International Program on Chemical Safety, European Union Chemical Bureau, the EPA and other international and national programs and agencies are widely used by researchers and practicing specialists.

In accordance with OECD recommendations on risk assessment of chemical substances, the initial stage of research is to find information about the substance and its analogues in the database, and only then carry out experimental work to the extent necessary. The ultimate objective of toxicological studies is to provide interested users with access to the information obtained by means of information technology. Unfortunately, popular foreign information and referral systems do not always correspond with the country's system of risk assessment and hygienic regulation of chemicals, are not often translated in Russian; moreover, some of them are closed to the public. Scientific substantiation of the concept of state registration of potentially hazardous chemical and biological agents and its implementation in the Russian Federation as a form of hygienic regulation and information security problems of chemical safety has allowed to develop the basic principles of automated distributed information retrieval system (ARIPS) "Hazardous substances" (certificate of state registration database №2009620521 dated 28.10.2009), an official database on toxicity and hazards of chemicals Rospotrebnadzora. ARIPS created by the Russian Register of Potentially Hazardous Chemical and Biological Substances, allows for the collection and systematization of information on the matter in accordance with a set of indicators to assess the hazards of the substance, science-based and harmonized with the recommendations of the OECD, is used by federal executive bodies for the development and management decisions to minimize the risk of exposure to a chemical agent; bodies and organizations Rospotrebnadzora during the expert and research in order to state registration in the framework of the Customs Union Agreement on sanitary measures; to carry out scientific 
research; for inclusion in the normative and technical documentation for the product, the development of the safety data sheet on the connection, for the classification of waste production and consumption, as well as the classification of substances according to Annex 1 of the Federal Law "On industrial safety of hazardous production facilities» № 116-FZ of 21 July 1997 (new wording of 02.07.2013) [2].

Scientific substantiation of the concept of state registration of potentially hazardous chemicals and biological agents and its implementation in the Russian Federation as a form of hygienic regulation and information base for the issues of chemical safety has allowed to develop the basic principles of automated distributed information retrieval system (ADIRS) "Hazardous substances" (certificate of the state registration database №2009620521 dated 28.10.2009), an official database on toxicity and hazards of chemicals by Rospotrebnadzor. ADIRS created by the Russian Register of Potentially Hazardous Chemical and Biological Substances, allows for the collection and systematization of information on the matter in accordance with a set of indicators to assess the hazards of the substance, science-based and harmonized with the recommendations of the OECD, is used by the federal executive bodies for the development and management of decisions to minimize the risk of exposure to a chemical agent; Rospotrebnadzor agencies and organizations during the expert and research studies for the purpose of state registration in the framework of the Customs Union Agreement on sanitary measures; for scientific research; for inclusion in the normative and technical documentation for the product, the development of the safety data sheet on the connection, for the classification of waste production and consumption, as well as the classification of the substances according to Amendment 1 of the Federal Law "On industrial safety of hazardous production facilities» № 116-FZ of 21 July 1997 (new wording of 02.07.2013) [2].

Current version of the automated information search system 'Hazardous Substances' contain over 420 characteristics of approximately 10000 chemical substances including information about the class of hazard explained by their physical and chemical properties, health and environmental hazard, according to GHS.

Rospotrebnadzor fulfils the obligations in regards to the transport and disposal of hazardous waste imposed by the Basel Convention, Stockholm Convention on persistent organic pollutants, and Rotterdam convention on the procedure of a preliminary informed consent in regards to some chemical substances and pesticides in the international trade. Implementation of the conventions requires international coordination, active involvement of business and public organizations.

To summarize, the analysis of modern trends in chemical substances circulation abroad 
and their implementation in Russia shows:

Acknowledgement of the chemical factors as an integral hazard to public health and the environment which requires joint regulatory efforts;

Necessity to harmonize domestic regulatory database with the international requirements; implementation of the Good Laboratory Practices and GHS into the hygienic and preventative toxicology practice; creation and implementation of a national program to study high-risk substances circulating in the market in order to replace them with safe substitutes.

\section{References}

1. Onishchenko G.G. Khimicheskaya bezopasnost' - vazhneyshaya sostavlyayushchaya sanitarno-epidemiologicheskogo blagopoluchiya naseleniya [Chemical safety is the most important constituent of the sanitary and epidemiological well-being of population]. Toksikologicheskiy vestnik, 2014, no. 1, pp. 2-6.

2. Federal'nyy zakon «O promyshlennoy bezopasnosti opasnykh proizvodstvennykh ob"ektov» ot 21.07.1997 №116-FZ [Federal Law of 21.07.1997 "Industrial Safety of Hazardous Production Entities" 116-FZ].

3. Anastas P.T.; Warner J.C. Green Chemistry: Theory and Practice, Oxford University Press: New York, 1998, p.30.
4. GHS
(Rev.
$5)$.
UNECE,
2013.
Available
at:

http://www.unece.org/trans/danger/publi/ghs/ghs_rev05/05files_e.html. 